further elucidation, ${ }^{5}$ but one study reported HIV seroconversion among $3 \%$ of men who had had single exposures to prostitutes in Nairobi. ${ }^{6}$ The study indicated that this 30 -fold increased risk was attributable mainly to sexually transmitted diseases (especially genital ulcerative diseases) in these prostitutes. In women the inflammation associated with sexually transmitted diseases may be asymptomatic and continue for many weeks or become chronic when untreated. A prostitute who had inflammation associated with a sexually transmitted disease for one fifth of the year and 200 partners during this period would thus infect six of them, whereas she would infect perhaps one partner during the four fifths of the year when no inflammation was present.

Condoms are the least expensive approach to controlling sexually transmitted diseases and have the added virtue of providing barrier protection against HIV. Schemes promoting the use of condoms are already under way in most parts of the world, with varying degrees of success. In many countries resistance to using condoms continues - from men (who consider that they reduce sexual pleasure), from their wives or girlfriends (who believe that they encourage promiscuity), and from those offended on religious or cultural grounds. Condoms need promoting, but additional innovative strategies are needed.

Although the record of success in controlling sexually transmitted diseases with antibiotics is not encouraging, attacking the HIV epidemic at this point is at least a possibility. Treatment of sexually transmitted diseases has intrinsic merit in improving personal health, a strong selling point for enlisting cooperation. Clinics and staff, however, cost money. Furthermore, although treatment for simple conditions may not be expensive, treating resistant strains of infecting organisms adds greatly to the cost. In many Third
World countries the annual public sector budget for all health programmes is roughly $\$ 10$ per person. Clearly, outside funds will be needed if programmes to control sexually transmitted diseases are to be expanded.

But success will depend not only on money. Scientists must develop practical technologies for diagnosing sexually transmitted diseases rapidly and new drugs for treating such diseases safely, simply, and cheaply. Just as important are new strategies appropriate to local conditions. These include increasing the use of paraprofessionals licensed to diagnose and treat sexually transmitted diseases, schemes to market effective but inexpensive generic antimicrobial agents, and mass campaigns to treat sexually transmitted diseases in high risk people throughout an area. Such approaches will not halt the HIV epidemic, but in a crisis of this size they should not be overlooked.

International AIDS Coordinator,

ROBERT J BIGGAR

Viral Epidemiology Section,

National Cancer Institute,

Rockville,

Maryland 20850

USA

1 Center for International Research (Health Studies Branch). Recent HIV seroprevalence levels by country: February, 1991. Washington, DC: US Bureau of the Census, 1991. (Research Notes No

2 Brookmeyer R. Reconstruction and future trends of the AIDS epidemic in the United States. Science 1991;253:37-42.

3 Working Group on Standard Input Values for values for modelling the impact of the AIDS epidemic. In: The AIDS epidemic and its demographic consequences. Geneva: World Health Organisation Global Program on AIDS, 1991:5-16. (United Nations publication No E.91.XIII.5.)

4 Neequay AR, Neequaye JE, Biggar RJ. Factors that could influence the spread of AIDS in Ghan West Africa: fournal of AIDS 1991;4:914-9.

Mertens TE, Hayes RJ, Smith PG. Epidemiological methods to study the interaction between HIV infection and other sexually transmitted diseases. AIDS 1990;4:57-65.

6 Cameron DW, Simonsen JN, D'Costa LJ, Ronald AR, Maitha GM, Gakinya MN, et al. Female to male transmission of human immunodeficiency virus type 1: risk factors for seroconversion in men. Lancet 1989;ii:403-7.

\title{
AIDS surveillance in Africa
}

\section{Time to rethink case definitions}

Surveillance of the AIDS pandemic in Africa has always posed formidable problems for epidemiologists. Diagnostic accuracy - according to the case definitions for AIDS used in industrialised countries - is impossible to achieve in all but a few places with the right diagnostic facilities. Responding to the urgent need for surveillance, the World Health Organisation drew up a clinical case definition (the WHO/Bangui definition), which depended on clinical criteria without the need for serological verification. ${ }^{12}$

Judged by its use, the WHO/Bangui definition has been successful-52 African countries have reported cases of AIDS using mainly this definition. ${ }^{3}$ Some countries have modified it to fit local circumstances, removing a defining symptom here, adding the need for an extra sign there, and many now accept or encourage a positive result of an HIV test as supportive evidence. (At least one, Côte d'Ivoire, requires such a result. ${ }^{2}$ )

Inevitably the definition has its limitations, and two papers in this week's journal discuss these at length (p 1185', p 11894). Because of limited laboratory facilities published evaluations of the WHO/Bangui definition have been mainly restricted to groups of sick patients using HIV positivity as the reference standard. The definition's sensitivity and specificity have been calculated as being between $60 \%$ and $90 \%{ }^{25}$ - useful for purposes of surveillance, but leaving uncertainty over whether this surveillance tool is intended to monitor trends in cases of AIDS or HIV infection. Other problems exist with the WHO/Bangui definition. Because many doctors lack diagnostic facilities they use the definition for diagnosis. The title "clinical case definition" encourages this confusion. The misuse is disturbing as the probability that a patient who fulfils the WHO/Bangui definition tests positive for HIV may fall well below $50 \%$ when seroprevalence is low. ${ }^{5}$

Another problem of using the definition is the delayed and incomplete picture that it gives of the spread of infection. ${ }^{6} \mathrm{Far}$ preferable for surveillance of infection is the unlinked anonymous testing for HIV of sentinel groups attending health services ${ }^{67}$ (such as pregnant women and people with sexually transmitted diseases), which has now begun in several African countries ${ }^{89}$ using the same methods as in industrialised countries. ${ }^{10}$

Where does this leave the WHO/Bangui definition? De Cock and colleagues rehearse the overwhelming case for AIDS reporting to continue and suggest a thoughtful redesign of the definition, which includes the requirement for a positive HIV test result. ${ }^{3}$ Insisting on positive test results in all circumstances, however, is impractical: HIV tests are already limited and are likely to become more so as AIDS funding to Africa inevitably falls. As a provisional solution to the 
problem of surveillance the WHO/Bangui definition has been useful, but the time has come for its reappraisal.

ANGUS NICOLL

Consultant Epidemiologist,

HIV, Hepatitis, Sexually Transmitted Disease Division,

PHLS AIDS Centre,

Communicable Disease Surveillance Centre,

London NW9 5EQ

Head, Department of Epidemiology and Biostatistics, JAPHET KILLEWO

Muhimbili University College of Health Sciences,

Dar es Salaam,

Tanzania
World Health Organisation. Provisional WHO clinical case definition for AIDS. Wkly Epidemio $\operatorname{Rec}$ 1986;62:72-3.

2 De Cock K, Selik R, Soro B, Gayle H, Colebunders RL. AIDS surveillance in Africa: a reapprais of case definitions. BMF 1991;303:1186-88.

3 World Health Organisation. Acquired immunodeficiency syndrome (AIDS) - data as at 1 October 1991. Wkly Epidemiol Rec 1991;66:289-90.

4 Gilks C. What use is a clinical case definition for AIDS in Africa? BMf 1991;303:1189-90.

De Cock K, Colebunders R, Francis H, Nzilambi N, Laga M, Ryder R, et al. Evaluation of the WHO clinical case definition for AIDS in rural Zaire. AIDS 1988;2:219-21.

Chin J. Public health surveillance of AIDS and HIV infection. Bull World Health Organ 1990;68:529-36.

World Health Organisation. Unlinked anonymous screening for the public health surveillance of HIV infections. Proposed international guidelines. Geneva: WHO, 1989. (GPA/SF1/89.3.)

Global Programme on AIDS. Sentinel HIV surveillance, Central African Republic. Wkly Epidemiol Rec 1991;66:257-9.

Ministry of Health, United Republic of Tanzania. National AIDS control program. AIDS Surveillance Report no 4 . March, 1991.

10 Gill ON, Adler MW, Day NE. Monitoring the prevalence of HIV. BMJ 1989;299:1295-8.

\section{Parent support groups}

\section{Doctors should work closely with them}

Being told that your child has special needs and disabilities is probably one of the most painful experiences that a parent may have to go through. ${ }^{1}$ No matter how carefully the problems and the prognosis are explained, this may not be enough - as this week's personal view shows ( $p$ 1208). ${ }^{2}$ Many families will be devastated and feel very isolated.

Contact with other families with similarly affected children may be comforting - firstly, because they have shared similar experiences and, secondly, because they are not professionals, who are often perceived as too busy or intimidating. Finding these other parents may be difficult, and many parent support groups have been set up to facilitate this. Now the charity Contact a Family has published a directory of specific conditions and rare syndromes in children together with their support networks. ${ }^{3}$ This is an invaluable source of information for all those looking after children with chronic disorders. All families should at least have the opportunity of establishing contact with other families - even if they do not want to take it up. Some of those who do will be upset and confused by well intended support, a problem that those who run the groups will need to recognise.

The value of parent support groups extends far beyond just providing support for families. Many parents want to help advance the understanding of their child's condition, and support groups may provide substantial funds for research. They can also provide information for all those caring for affected children. Some families are eager for more information, which health professionals may also find useful. Helpful practical advice about all aspects of management can be compiled.

Support groups may have a role in improving medical care, although this has not yet been fully recognised. Many parent support groups hold meetings for all parties concerned to discuss problems. Speakers may include parents or patients talking about their own experiences and views in their own terms. I doubt if there is a doctor who could not learn from listening to such a talk. Having to sit through the talk of a parent who has lost children under your care can be a chastening experience. This is an important form of audit. The potential value of a coordinated voice of patients and parents to improve all aspects of care should not be underestimated. With the emphasis on the patient's voice it may not be so easy for managers and the government to ignore issues of underfunding, poor service, and inadequate facilities.

Doctors tend to be suspicious of parent (or patient) power, but they should recognise the importance of these groups. They have a valuable contribution to make, and we should all work closely with them.

JV LEONARD

Reader in Child Health,

Institute of Child Health

London WC1H $1 \mathrm{EH}$

1 Youngs C. Contact a family. British Inherited Metabolic Disease Group Newsletter 1991;3:23-6.

2 Gerrard A. We have a metabolic disease. BMf 1991;303:1208.

3 Contact a Family. The $\mathrm{CaF}$ directory of specific conditions and rare syndromes in children with their family support networks. London: Contact a Family, 1991. 